\title{
IDENTIDADE DOCENTE NO ENSINO SUPERIOR DE EDUCAÇÃO FÍSICA: ASPECTOS EPISTEMOLÓGICOS E SUBSTANTIVOS DA MERCANTILIZAÇÃO EDUCACIONAL
}

\author{
IDENTITY OF PHYSICAL EDUCATION TEACHERS IN HIGHER EDUCATION: \\ EPISTEMOLOGICAL AND SUBSTANTIVE ASPECTS OF COMMODIFICATION OF EDUCATION
}

\begin{abstract}
LA IDENTIDAD DEL PROFESOR EN LA EDUCACIÓN SUPERIOR DE EDUCACIÓN FÍSICA: ASPECTOS EPISTEMOLÓGICOS Y SUSTANTIVOS DE LA MERCANTILIZACIÓN EDUCATIVA
\end{abstract}

Rubens Antonio Gurgel Vieira*, Marcos Garcia Neira ${ }^{* *}$

Palavras chave: Educação Superior. Currículo. Mercantilização. Docentes.
Resumo: Partindo do pressuposto de que a complexidade da sociedade contemporânea interpela os sujeitos de diversas formas, investigou-se o processo de construção identitária de docentes universitários. Para tanto, optou-se pelo método de história oral temática como forma de investigar a constituição da identidade do professor responsável por disciplinas didáticopedagógicas dos cursos de licenciatura em Educação Física situados na cidade de Sorocaba/ SP. As análises baseadas nos pressupostos dos Estudos Culturais e divididas em aspectos epistemológicos e substantivos indicam a presença marcante de identidades docentes acríticas e solitárias, fruto de trajetórias de vida e subjetivações constituídas mediante relações de poder e processos sócio-históricos que mercantilizam a educação e que levam à instauração de práticas alienantes nas instituições de ensino superior. Dentre as estratégias necessárias para superar essa conjuntura, destaca-se a contínua expansão do debate acadêmico com 0 recurso de ferramentas teóricas contemporâneas que confiram visibilidade aos conhecimentos produzidos no contexto escolar.

\section{Keywords:}

Education, Higher.

Curriculum.

Commodification.

Faculty.

\begin{abstract}
Based on the assumption that contemporary society's complexity challenges subjects in many ways, we investigated the construction of university professors' identity. To this end, we chose the oral history method to investigate the constitution of the identity of the professor in charge of didactic and pedagogical subjects in PE courses in the city of Sorocaba, SP, Brazil. Analyses based on Cultural Studies assumptions and divided into epistemological and substantive aspects indicate strong presence of uncritical and solitary teacher identities, as a result of life histories and subjectivities constituted by power relations and socio-historical processes that commodify education and lead to alienating practices in higher education institutions. The strategies to overcome that situation include continued expansion of the academic debate using contemporary theoretical tools that give visibility to knowledge produced in the school context.
\end{abstract}

\section{Palabras clave:} Educación Superior. Mercantilización. Docentes
Resumen: Partiendo del presupuesto de que la complejidad de la sociedad contemporánea desafía a los sujetos de muchas maneras, se investigó el proceso de construcción identitaria de los profesores universitarios. Para ello, se optó por el método de historia oral como forma de investigar la formación de la identidad del profesor responsable por materias didáctico- pedagógicas de los cursos de Licenciatura en Educación Física ubicados en la ciudad de Sorocaba (SP). Los análisis basados en los presupuestos de los Estudios Culturales y divididas en aspectos epistemológicos y sustantivos, indican la fuerte presencia de identidades docentes acríticas y solitarias, fruto trayectorias de vida y subjetividades constituidas mediante relaciones de poder y procesos socio-históricos que mercantilizan la educación y llevan a la instauración de prácticas alienantes en las instituciones de educación superior. Entre las estrategias necesarias para superar esta situación, se destaca la continua expansión del debate académico con la ayuda de herramientas teóricas contemporáneas que den visibilidad a los conocimientos producidos en el contexto escolar.contenidos aplicados y aprendizaje de los alumnos.
*Universidade Estadual de Campinas. Campinas, SP, Brasil. E-mail: rubensgurgel@hotmail.com

**Universidade de São Paulo. São Paulo, SP, Brasil. E-mail: mgneira@usp.br

Recebido em: 18-04-2015 Aprovado em: 13-01-2016

(c) (1) (8) Licence 


\section{INTRODUÇÃO}

Os Estudos Culturais configuram um campo teórico que compreende a cultura como arena de disputas, um território onde os grupos humanos lutam pela hegemonia de seus valores, comportamentos e desejos. Na visão de Escosteguy (2006) e Johnson (2006), tratase de uma ampliação da perspectiva antropológica que denomina por cultura toda produção humana.

Os confrontos das arenas culturais se dão em torno do poder de representar os significados, regulando os discursos e seus processos classificatórios. Para os Estudos Culturais, a linguagem interpela por meio da sedução e convencimento, ou através de um processo de investimento que acaba por gerar a identificação. Posto dessa forma, é lícito dizer que o poder opera subjetivações, constituindo identidades alheias à vontade do sujeito. Consequentemente, as identidades são constituídas como atos de poder no interior de relações complexas. É o ponto de apego (ou sutura) entre os discursos e práticas que convocam os sujeitos a assumirem determinadas posições, subjetivamente temporárias, contextuais e contingentes (HALL, 2001).

Se considerarmos que há grupos com mais poder que outros para representar os demais e fazer valer a sua voz, e entendermos o mercado e a lógica neoliberal como vetores de maior força, compreende-se que os discursos educacionais contemporâneos posicionam os docentes ao colocarem em circulação representações sobre como devem ser e agir, sujeitando as suas identidades.

Em tempos de intensificação das políticas de identidade, ou seja, de disputas cada vez mais acirradas pelas representações que sustentam o sujeito ideal, ser professor é estar imerso em lutas por concepções, sem que haja neutralidade nas opções teóricas e, consequentemente, políticas. Se o conhecimento veiculado durante a formação influencia futuras identidades profissionais e culturais, a determinação do que e como será ensinado é uma decisão política com efeitos diretos no contexto mais amplo. Toda essa trama influi decisivamente nas noções de sociedade, educação, currículo e ensino de Educação Física dos professores que atuam nos cursos de licenciatura, ou seja, impactam a sua docência.

Devido ao caráter heterogêneo da identidade docente, faz mais sentido falarmos em identidades docentes, no plural. Essas identidades estão sendo forjadas nos currículos substantivos e epistemológicos da Educação Física, onde o conflito entre diferentes óticas do componente resulta em disputas amplas dentro do contestado terreno curricular. Inspirados na definição de Du Gay (apudWOODWARD, 2008), denominamos de currículos epistemológicos ${ }^{1}$ aqueles aspectos do currículo da licenciatura em Educação Física que agregam conceitos e conhecimentos sobre como deve ser a prática pedagógica, a relação com os alunos, seleção de conteúdos e instrumentos de avaliação, além da condição político-pedagógica - em suma, sua forma de ensinar. Por sua vez, o currículo substantivo é compreendido como aquele efetivado na Instituição de Ensino Superior (IES), através de relações moldadas pelo poder ali disseminado, a depender das condições específicas. Conforme asseveram Neira (2009) e Nunes (2011), a arena de lutas que compõe o processo de formação dos futuros docentes não é uniforme, nem tampouco livre de contradições em seus objetivos e conteúdos. 
Com este pano de fundo, e amparados pelos conceitos de currículo (SILVA, 2007) e identidade (HALL, 2001, 2008), coletamos histórias de vida através de entrevistas pautadas na metodologia da história oral. A história oral (com letras minúsculas, para reforçar seu aspecto rebelde) está presente em diversas disciplinas das ciências humanas, o que lhe permitiu a aquisição de um status multidisciplinar, além do seu emprego frequente como estratégia a favor de populações oprimidas. Seguindo os pressupostos de Meihy (1996) e Meihy e Holanda (2010), adotamos a história oral temática, forma metodológica de história oral que concentra esforços e atenção em pontos temáticos específicos do colaborador da pesquisa. Através dos registros das manifestações da oralidade humana, as percepções da vida social são utilizadas para explicar determinados contextos.

O método de pesquisa história oral é distinto do simples ato de entrevistar para se obter informações objetivas. Um projeto de história oral não omite do leitor o contexto da sua produção, mas promove outros significados para fatos estabelecidos. Este viés de pesquisa é coerente com a preocupação dos Estudos Culturais, ao pretenderem aprofundar os significados reinantes, refazendo o percurso histórico de formação e movimentação social. "Nosso projeto é o de abstrair, descrever e reconstituir, em estudos concretos, as formas através das quais os seres humanos vivem, tornam-se conscientes e se sustentam subjetivamente" (JOHNSON, 2006, p. 29).

No caso em tela, procuramos reunir as passagens marcantes das vidas dos docentes entrevistados e estimulamos a abordagem de questões-chave para a compreensão de suas identidades como, por exemplo, as bases epistemológicas de seus discursos pedagógicos e as condições substantivas de sua ação didática. Tal ato pretendeu não somente angariar informações, mas também validar histórias subjugadas.

Constituíram-se como sujeitos da pesquisa professores que atuam em cursos de licenciatura em Educação Física da cidade de Sorocaba (SP). O estudo investigou o processo de construção das identidades docentes por meio da elucidação dos discursos e saberes que as cercam e constituem, problematizando como chegaram a ser o que dizem que são e como foram engendradas nessa história. Participaram do estudo um professor ou professora de cada uma das cinco IES que oferecem o curso na cidade - todas são privadas. No período da realização das entrevistas, os docentes eram os principais responsáveis, em seus respectivos cursos, pelas disciplinas denominadas "pedagógicas" (Didática, Metodologia do Ensino de Educação Física e Prática de Ensino).

A professora Fabiana ${ }^{2}$ concluiu o mestrado em Educação Física com foco na biodinâmica do movimento humano e atua no Ensino Superior há oito anos. O professor Gian e a professora Rosa são mestres em Educação, com seis e sete anos de experiência, respectivamente. 0 professor Marcelo atua há nove anos e é doutorando em Educação, e a professora Rafaela cursa o mestrado em Educação em Saúde e tem nove anos de experiência.

Após a transcrição literal das entrevistas, realizou-se a "transcriação", processo que caracteriza a metodologia da história oral e que consiste basicamente na produção de um texto em parceria com o colaborador, que pode, inclusive, suprimir ou incluir passagens, pois o que importa é a sua visão do que foi criado. O material resultante foi submetido ao confronto com os Estudos Culturais, buscando nos discursos as identificações (presentes nos aspectos epistemológicos) e posições de sujeito (referendadas nos aspectos substantivos) que sustentam suas identidades. 


\section{ASPECTOS EPISTEMOLÓGICOS: DISCURSOS A FAVOR DAS COMBINAÇÕES CURRI- CULARES}

O currículo que forma futuros professores é produto de tensões, descontinuidades, rupturas e disputas culturais, sociais e políticas. Quando alinhado a concepções acríticas, favorece interesses distantes da coletividade. Isso refletirá uma concepção de Educação Física que passa ao largo das injustiças sociais. Neira e Nunes (2009) discutem como o poder age nos currículos do componente de modo a construir identidades afeitas a determinados interesses, buscando distinguir as visões de sociedade, ensino e sujeito da educação implícitas nas propostas acríticas (esportivista, desenvolvimentista, psicomotora e educação para a saúde), críticas (crítico-superadora e crítico-emancipatória) e pós-críticas (cultural ou multicultural).

Investigar a identidade docente é atentar para o contexto, desde aspectos da gestão do Estado até as especificidades do componente curricular, passando pela visão de rede de ensino, cotidiano da escola e interação com os alunos. É analisar os discursos e práticas de significação que classificam estes espaços, posicionam seus sujeitos e compõem a cultural local. Inicialmente, buscamos identificar nos discursos indícios dos currículos de Educação Física Escolar nos quais os docentes se inspiram, o que possibilitou visualizar certo ecletismo conceitual.

\footnotetext{
Eu não acredito em 'eu sou isso, eu tenho que fazer isso'. Fui formada assim, mas eu tenho a percepção clara que só isso não existe. Tanto é que eu me afastei agora do Estado (São Paulo), sou professora efetiva do Estado também, seis anos... e nunca fui desenvolvimentista. Para falar a verdade, a que eu menos uso é a da psicomotricidade, porque eu acho que nada mais é que outro nome: desenvolver a parte cognitiva através do movimento, é a mesma coisa (Professora Fabiana).

Eu sempre fui uma professora que gostava de fazer coisas diferentes, atividades diferentes, propostas diferentes (Professora Rafaela).

[...] trabalhar usando as ferramentas lúdicas, porque com elas você consegue desenvolver 0 trabalho. Basicamente as ações são pautadas em modalidades lúdicas. No ensino médio era mais voltado para o esporte, mais para a iniciação esportiva (Professor Gian).
}

Para Burke (2006), em cada espaço social e histórico a combinação de culturas pode ser compreendida como uma hibridização. Se compreendermos os conceitos que sustentam as práticas pedagógicas docentes como produções culturais, podemos considerar o ecletismo no campo da Educação Física Escolar como um hibridismo curricular.

Suspeitando que o hibridismo curricular seja um elemento comum a vários profissionais, decidimos que não seria recomendável desenvolver o tema de forma direta. A estratégia utilizada foi estimulá-los a narrar outros aspectos que envolvessem as identidades, como questões macro acerca da posição da Educação Física na educação e na sociedade, e questões micro, sobre a atuação em sala de aula no passado e no presente, além das principais referências teóricas utilizadas como base para a prática pedagógica. $O$ procedimento evidenciou uma concepção de área difusa, com representações diversas a respeito da função do componente na escola.

Nas entrevistas transcriadas, alguns discursos proferidos levam a crer que a compreensão dos docentes acerca da crise epistemológica e identitária da área (BRACHT, 2003) ora é superficial, ora não se apresenta. Na direção oposta ao que se poderia esperar de professores universitários, o mais comum foi encontrar a defesa da Educação Física através do 
seu viés biológico, ignorando as transformações e tensões no campo que buscam substituir o estatuto epistemológico da psicobiologia pelas ciências humanas.

É um espaço da área da saúde, uma área que custou muito para sermos inseridos. Demorou muitos anos, mas agora nós somos da área da saúde. Educar para a saúde, juntando os dois, para a qualidade de vida, para sermos pessoas positivas, para o movimento (Professora Rafaela).

Os docentes que se alinham aos currículos acríticos da Educação Física colocam em circulação discursos que exaltam o desempenho corporal sem questionar as desigualdades, sendo insensíveis às necessidades de transformação social em favorecimento às minorias oprimidas. É preocupante, portanto, que alguns docentes se encontrem à margem da discussão e não apresentem posicionamentos sobre a crise que acomete o campo, tampouco abordem o surgimento do currículo cultural como alternativa ao que vinha sendo feito, mesmo que a produção teórica que lhe dá sustentação já exista há algumas décadas. As raras menções evidenciam que as posturas crítica e pós-crítica encontram pouco eco entre os formadores de professores.

Quando não se tem clareza epistemológica dos currículos da Educação Física Escolar, as opções teóricas que fundamentam os discursos e instituem identidades docentes podem se apoiar na tradição, comodismo ou pressões político-pedagógicas. Mesmo que não haja explicitação desses condicionantes na voz dos professores, inexiste posicionamento desconectado da disputa cultural. A interdição dos discursos que deslocam representações tradicionais e acríticas deixa mostras de operações de poder mais amplas.

Todavia, se recuperarmos os argumentos de Silva (2007), para quem o currículo forja identidades não somente discentes como também docentes, será lícito afirmar que o currículo da licenciatura em Educação Física é fonte de representações também para os professores que nele atuam, conferindo-lhes significados específicos com respeito à concepção de escola, aluno, ensino, aprendizagem e docência. Não se pode pensar que somente os professores disseminam noções enviesadas sobre a prática escolar, pois o próprio currículo que lhes dá guarida faz o mesmo com eles, o que os torna criadores e criaturas simultaneamente (NUNES, 2011).

[...] tentando fazer uma avaliação do que eu vivi nesta faculdade, os alunos que passaram por mim, daquela ideia do currículo meio 'Frankenstein', com várias correntes permeando a prática de coisas que não se conversam, mas que muitas vezes a gente utiliza (Professora Rosa).

Os discursos curriculares são variados, controversos e coexistentes. Isso explica 0 sentimento de pertencimento a instituições, ações, convenções e decisões contraditórias que assolam os indivíduos pós-modernos (HALL, 2001). Neste sentido, o mesmo professor pode se identificar com distintos posicionamentos curriculares, compostos por múltiplos discursos que manifestam visões de sociedade, educação, escola e Educação Física divergentes.

Com relação a autores, o que eu tenho usado bastante é a Tizuko Kishimoto, porque ela tem uma área bem desenvolvida nesta questão dos conceitos do jogo, nesta questão do brincar, né, e tem muito a ver com a Educação Física Infantil. 0 Neira também é um autor que eu uso bastante, principalmente nas discussões da questão da Educação Física Escolar, com várias abordagens importantes. Bom, aí tem outros, né, para a análise motora eu costumo usar o Gallahue. Tem vários, tem a Catarina Rodrigues, que fala da Educação infantil; João Batista Freire é um autor 
que às vezes eu gosto de usar, tem umas ideias bacanas; na Educação Física, que eu tenho usado bastante, é a Gisele, não me recordo do sobrenome, que tem vários artigos que eu tento usar (Professor Gian).

Frente à evolução do debate acadêmico acerca dos currículos da Educação Física Escolar, os docentes precisam constantemente rever seus posicionamentos, acomodar suas identidades ante os abalos e provocações que circulam entre os sujeitos que fabricam e são fabricados neste substrato da cultura. Muitas vezes impossibilitadas de incursões mais profundas, as reflexões docentes recorrem ao senso comum em busca de respostas. Em diversos contextos essa limitação é reforçada pelas condições substantivas da ação docente, que não favorecem a pesquisa, o estudo sistemático, o diálogo com o campo científico e seus pares. Assim, para os docentes, não é possível participar de eventos científicos ou reuniões pedagógicas que proporcionem o aprofundamento e a ampliação da visão de campo e função docente.

Uma vez que o processo de diferenciação identitária se vincula aos sistemas de significação, quando se questiona uma dada identidade, a rigor, o que se está a fazer é questionar os sistemas representacionais em que está lastreada. Quando as indagações acerca da função social da Educação Física apontaram seu papel na reprodução das desigualdades sociais, a crise que sucedeu às primeiras formulações baseadas nas ciências humanas empurrou a área para uma busca frenética por sentido, resultando no clima de incertezas com sérias consequências para as identidades docentes.

Diante das contestações dirigidas aos aportes teóricos que sustentavam discursos e práticas, as identidades docentes de Educação Física foram obrigadas a se reposicionar. Como conciliar as pressões da crítica educacional em conjunto com as identificações mais resistentes? Sendo uma das características da identidade dar guarida aos abalos psíquicos, e considerando que dúvidas desta espécie podem perturbar identidades docentes, se faz necessário encontrar uma alternativa, algo que sirva como válvula de escape. A combinação de currículos epistemológicos, ou seja, o hibridismo curricular acrítico, parece ter sido o caminho traçado pelos entrevistados. Nos dizeres de Silva (2008), trata-se de uma identidade normalizada - eleita arbitrariamente pela coletividade para servir como parâmetro na avaliação e julgamento das demais.

Hoje já se admite isso, 'isto da desenvolvimentista é legal, vou por aqui ó, agora isto da cultura, é legal também, vou por ali'. Junta-se tudo, sei lá, eu acho que dá para... mas isto é uma opinião minha que não estou na escola. Eu acho todas interessantes (Professor Marcelo).

O discurso curricular híbrido da Educação Física, consciente ou não das particularidades de cada proposta, dos dispositivos que a constituem e, principalmente, dos efeitos substantivos desencadeados pelos regimes de verdade que coloca em circulação, defende que a combinação dos currículos epistemológicos baseada na consideração dos pontos "positivos" de cada um situa-se no campo das possibilidades, mesmo que absolutamente desprovida quer seja de fundamentação teórica ou de embasamento empírico.

Nos pronunciamentos, que poderíamos chamar de acríticos, emitidos por alguns entrevistados há indícios que corroboram a confusão curricular e a superficialidade conceitual. Não obstante, nos raros discursos críticos, chama a atenção a curta experiência profissional na Educação Básica. De uma forma geral, os colaboradores alinhados a uma posição crítica da 
área não apresentaram histórico de atuação docente na escola. É o próprio docente que tece a crítica acerca das limitações que a falta de experiência no "chão da escola" pode trazer para quem trabalha nas disciplinas pedagógicas:

O professor de Ensino Superior vai lá, faz o mestrado, aconteceu comigo... pouquíssimo tempo fiquei na escola, seis meses fiquei na escola, como estagiário ainda, no primeiro semestre da faculdade e depois pintou academia, pintou mestrado e pintou Ensino Superior. Ou seja, o que eu posso falar de escola hoje? Que exemplos, que história eu tenho para contar? Só o que eu leio, só o que eu ouço, eu não estou no chão da escola (Professor Marcelo).

\section{ASPECTOS SUBSTANTIVOS: A MATERIALIDADE QUE ENVOLVE A SOLIDÃO DOCENTE}

Giroux (2003) denuncia a crise na cultura política, com o enfraquecimento das resistências aos discursos hegemônicos. A cultura política atua na intersecção entre representações simbólicas, vida cotidiana e relações materiais de poder. Todavia, está em processo um esmorecimento destas disputas, solapadas pelo enfraquecimento de esferas públicas democráticas. Tornou-se hegemônica no mundo contemporâneo a regulação pelo mercado, disseminando valores que delimitam a função das esferas públicas. Nos tempos em que vivemos, o Ensino Superior segue os mesmos princípios do meio empresarial e se sujeita a discursos e práticas que desprezam a diversidade cultural e a democracia.

Com base nos Estudos Culturais, a diversidade cultural implica não somente a coexistência e circulação de significados provenientes de grupos distintos, como também o enfraquecimento, em meio a disputas sociais, de determinadas posições como decorrência da ação de forças homogeneizantes. Para exemplificar, a cultura branca, economicamente favorecida, masculina, cristã e heterossexual apresenta enorme vantagem na imposição dos seus interesses diante daquelas que veiculam outros valores e representações (MCLAREN; GIROUX, 2007).

A dominação das esferas públicas por corporações financeiras submete suas lógicas de funcionamento, cada vez mais, aos valores de mercado, tais como competição, meritocracia, lucro e competências de atuação. Na docência isto é explicitado quando a ação do professor é mercantilizada e sujeita às mesmas pressões mercadológicas que atingem outros produtos.

Hoje a gente tem uma pressão pelo ENADE. A gente é pressionado pelos estudantes. Só que depende muito da estrutura, da organização, de como a entidade é no trabalho com você. $O$ grande problema hoje é que as faculdades são negócios. Tanto é que eu entrei em uma instituição e agora sou outra. 0 projeto que era feito, você comprou, acabou, agora essa daqui é de outro jeito, os valores das provas são outros, mudou! A bolsa que eu tinha no Prouni não tenho mais porque vendeu! A questão do ENADE põe bastante pressão, mas joga muita pressão no professor, sendo que a estrutura para você trabalhar também influencia (Professora Fabiana).

Ser professor nestas condições é exercer uma profissão sujeita a tensões e resistências nem sempre muito evidentes, pois os interesses, múltiplos e complexos, articulam tendências mundiais com influências locais. A globalização e os princípios neoliberais transformaram o Ensino Superior de reduto de esfera pública democrática, em centro de treinamento de novos profissionais para o mercado. 0 poder dos discursos que moldam estas relações regula a cultura institucional nos espaços democráticos muito mais pela interpelação (sedução) do que pela imposição. 
Deste modo, muitos cursos superiores são invadidos por novas formas de conhecimento apoiadas na noção de competências necessárias para a atuação no mercado de trabalho, entendido como uma arena dividida entre ganhadores e perdedores. Consequentemente, a função desempenhada pelo docente insere-se nesse contexto, seja na sua confluência, seja para resistir aos desejos predominantes. A lógica neoliberal calcada na produtividade, competição, meritocracia e empreendimento pessoal sobrepesa aos professores quando os obriga a desempenhar uma multiplicidade de funções e tarefas, pressionando-os a executálas no menor tempo possível, na urgência de resultados e na qualidade absoluta no fazer profissional, critérios orientados pela transformação da educação em mercadoria (NUNES, 2011).

O currículo substantivo orientado pela competitividade do mercado se traduz em dispositivo regulador na sala de aula, exercendo influência sobre identidades docente e discente, buscando uma subjetivação favorável à cultura hegemônica e negligenciando aspectos urgentes de desigualdade social e diversidade cultural. Isto ocorre porque as principais regulações institucionais estão orientadas para a sustentação financeira, cooptação de novos alunos, manutenção dos existentes e aumento do lucro. Logo, há pouco espaço e incentivo para identidades docentes preocupadas com questões democráticas.

Tem faculdade que se diferencia neste sentido. Tem faculdade que você é um número, tem faculdade que você é uma pessoa. Tem faculdade que vai te arrumar um estágio, que vai lembrar porque conhece 0 aluno. Neste ponto, as faculdades isoladas, eu acho que ganham de universidades com seus vários cursos. Os professores aqui dão aula só para este curso, não têm muitas turmas para dar aula, então é mais fácil colocar uma filosofia dessas. Como eu trabalho nas duas eu consigo ver esta diferença (Professor Marcelo).

Há um certo consenso acadêmico de que o Ensino Superior está em crise. As instituições universitárias enfrentam desafios crescentes, como cortes orçamentários, diminuição da qualidade, redução do corpo docente, militarização da investigação e reformulação do currículo para se adaptar às necessidades do mercado. Como consequência, líderes corporativos ou figuras políticas são contratados como reitores, docentes de carreira são substituídos por professores temporários, alunos são tratados como clientes e a aprendizagem é cada vez mais definida em termos instrumentais, enquanto o conhecimento crítico não encontra espaço no currículo (GIROUX, 2010). As vozes dos docentes entrevistados reverberam essas ideias em diversos momentos, reafirmando a regulação cultural exercida pelo currículo.

[...] o particular, assim, é muito difícil de você trabalhar. Eles te veem apenas como alguém que dá aula, se você não tem uma carga horária mínima lá, você não consegue sobreviver. Hoje, eu até comento em casa, eu tenho muito menos aulas do que os meus colegas, mas se eu falar para qualquer colega de uma universidade pública que hoje eu tenho 20 horas-aula em sala, vão achar um absurdo. Porque a gente tem que estudar, tem que rever, tem que preparar e sobra pouquíssimo tempo de fazer isso (Professora Rosa).

Os docentes entrevistados denunciam a instabilidade na profissão; a ausência de remuneração pelas atividades extraclasse, como orientação e correção; o processo pouco democrático e sem critérios pedagógicos para distribuição da carga didática; a ampliação da jornada de trabalho como alternativa para melhorar a remuneração; o pouco tempo para pesquisa e atualização; tudo isso coroado pelo contato distante e despreocupado com os alunos. 
[...] hoje, não se recebe mais orientação pelo TCC. Tenho que orientar, mas eu não recebo por isso. Consequentemente, essa experiência muito importante para o aluno, ele tem meia-boca. Eu estou em duas instituições, nenhuma paga orientação. As duas "exigem" que você oriente. Se você se negar é um motivo. Hoje eu estou no Ensino Superior, mas pode ser que por qualquer bobeira, mandem embora. Ou porque eu sou mestre vão querer pegar um especialista ${ }^{3}$. Ou porque eu me neguei a orientar um aluno. [...] se por acaso este semestre eu disser que não quero pegar uma disciplina, isto não vai ser legal. Porque eu acredito que não devo dar uma disciplina que não é do meu conhecimento. Isto é uma pressão que existe bem por detrás dos panos. [...] Eu acho que tudo está mais difícil, é portal, é aula pela internet, tudo o que você vai fazer é pela internet. Isto significa que você está trabalhando em casa. E não está ganhando por isso (Professora Fabiana).

A sequela da dominação por mecanismos de mercado é justamente a metamorfose dos significados de valor cultural e democrático do Ensino Superior: de missão de esfera pública produtora de conhecimentos a instrumento de um projeto hegemônico pouco compromissado com a melhoria da sociedade como um todo. Paulatinamente, 0 Ensino Superior vem deixando de ser um espaço dedicado à inovação intelectual e orientado pela busca de transformações que se alinham ao benefício público. Sua função de educar gerações e enfrentar os desafios contemporâneos foi corrompida com consequências políticas, sociais e éticas, enfraquecendo o compromisso com a vida pública ao se coadunar com a lógica neoliberal (GIROUX, 2010).

Regulado por uma cultura neoliberal macrocontextual, mesmo os currículos da licenciatura disseminam discursos que tentam fixar uma compreensão de sociedade baseada na lógica mercantil. Logo, discursar a favor de uma educação crítica dentro destas instituições não é tarefa fácil. Para manter seus empregos, os professores precisam atender a certos critérios de eficiência. Mais do que isso, precisam identificar-se com o projeto do mercado e até defendê-lo (NUNES, 2011).

Sendo a identidade constituída em meio à relação entre sujeição e identificação, os discursos e práticas de significação delineiam as posições de sujeito, delimitam as fronteiras, asseguram e naturalizam certos posicionamentos (WOODWARD, 2008). Para garantir que as identidades docentes não perturbem os limites impostos pela cultura empresarial (discursos mercadorizados, como a competição, meritocracia, qualidade total etc.), as IES se valem de recursos amparados nas ideologias empresariais como contenção de despesas, corte de custos e lucro maximizado, e pela própria legislação federal (BRASIL, 1996) quando, por exemplo, permite a desoneração dos cursos por meio da implantação de plataforma de estudos online que podem acomodar até $20 \%$ das disciplinas curriculares, entre outros aspectos.

Nesses contextos os professores são posicionados de forma distanciada de seus pares, assim como de um debate amplo dos propósitos da organização. A relação entre 0 Ensino Superior e neoliberalismo tem transformado as intenções educacionais e reproduzido o cenário recorrente nas áreas comerciais, o que resulta em precarização e proletarização do trabalho docente. Os professores atuam muitas vezes em uma estrutura organizacional que inviabiliza ações coletivas, sem disponibilidade de tempo para promover um ensino pautado pelo diálogo, pensamento, debate e reflexão sobre o trabalho que realizam.

3 Um discurso recorrente na área diz que, em tempo de grandes conglomerados educacionais, a lei do menor investimento possível obriga as instituições a contratar o número mínimo exigido por lei de mestres e doutores para o seu quadro docente. Neste contexto, há quem questione se é válido dar continuidade aos estudos pelo caminho stricto sensu sob pena de ser preterido por um especialista com menor salário. Muitas vezes, aqueles que insistem em prosseguir, se quiserem manter seus postos de trabalho, são obrigados a aceitar uma remuneração correspondente a profissionais de menor qualificação. 
No presente estudo, verificou-se que os docentes são ceifados do direito de participação em reuniões pedagógicas, oportunidade principal para discussão do projeto do curso e para 0 enfrentamento dos desafios cotidianos.

A única reunião que a gente tem é no início e no final do processo. Durante, não tem nenhum momento de troca, de reunião pedagógica... acho que... agora com 0 calendário da instituição a gente tem uma reunião, mas é aos sábados. Então não é uma convocação, é um convite, porque a gente não recebe. Há professores que trabalham em outro lugar, moram em outra cidade, então acaba sendo uma coisa meio fictícia (Professora Rosa).

Diante de condições que dificultam o debate com os parceiros e com a comunidade institucional, a prática da investigação ou mesmo o acesso a pesquisas produzidas em outros espaços, além da dificuldade de contato com discursos de fronteira (que não se limitam à lógica de mercado), parece ser bastante difícil na constituição de identidades solidárias à diversidade cultural presente, sobretudo nas escolas em que os egressos atuarão. Lutar pela diferença e diversidade cultural não tem o mesmo status dos discursos mercadológicos, e ainda traz "riscos de sobrevivência" à identidade docente. Se, porventura, o docente dá os primeiros passos para identificação com os discursos culturais, o sentimento pode ser de solidão em um contexto dominado pela ausência de criticidade:

Na verdade, eu me sinto como uma voz única dentro deste corpo docente. Quando a gente desenvolve algum trabalho, a gente percebe que os alunos têm uma visão assim mais física, mais biológica do movimento. Tanto é que você pega 0 planejamento que eles fazem e vai aparecer esta visão da Educação Física. E a gente acaba numa outra perspectiva, mas soando como uma voz que vai perdendo força. Você tem um grupo de sei lá, quinze professores defendendo uma Educação Física ligada à questão da saúde e atividade física e tem você lá, meio que sozinha tentando mostrar outras possibilidades para eles também, da cultura corporal. Então é esta arena, campo de lutas (Professora Rosa).

É mais seguro portar identidades tradicionais da área do que enfrentar as relações de poder existentes. No cotidiano, busca-se fazer o melhor possível em meio às necessidades básicas, às dificuldades inerentes ao processo e às condições impostas pelo contexto. $\mathrm{A}$ conjuntura da docência nas narrativas estudadas apresenta diversos momentos de isolamento, ora frente ao fazer pedagógico, ora frente às dificuldades inerentes à profissão. Há, portanto, um "professor solitário". Esta expressão se refere aos vários momentos em que os docentes se identificam, por interpelação ou por imposição regulatória, com posições de sujeito que subjetivam sentimentos de solidão. Não estamos nos referindo a uma essencialização ou condição estática que aflija a todos os docentes, mas a uma série de discursos, representações, práticas de significação e conjunturas que configuram contextos solitários no cotidiano das IES. Consequentemente, as opções teóricas e metodológicas dos professores entrevistados não são mera preferência individual, mas, sim, resultado do processo acima descrito.

\section{AS TRANSFORMAÇÕES NECESSÁRIAS}

Se, por um lado, defendemos que os docentes busquem acessar outros discursos, reflitam sobre os condicionantes da sua posição e questionem os fatores que lhes impõem amarras hegemônicas, os aspectos substantivos das suas vidas denotam uma série de concatenações materiais, discursivas e simbólicas orquestradas por tendências globais que 
limitam a atuação crítica. Com um número elevado de aulas, pressionados por resultados em exames nacionais, satisfação dos alunos, orientação de trabalhos, correção de provas e outros afazeres profissionais, é fácil compreender a dificuldade dos docentes em produzir novos conhecimentos, acompanhar os debates contemporâneos, participar de congressos, analisar as próprias práticas e base teórica para instaurar mudanças.

A desestabilização das identidades docentes acríticas e naturalizadas no contexto pesquisado requer a compreensão de que o processo de identificação não é preexistente a qualquer ação cultural, mas constantemente recriado, fruto de uma produção social (conflituosa) de atribuição de significados. Daí ser importante descobrir como a identificação é produzida nos diversos contextos sociais, questionando sua conformação. A desconstrução exige que a repetição dos discursos hegemônicos seja contestada e que outros enunciados sejam postos em circulação.

Propomos que novos discursos circulem em substituição aos hegemônicos acríticos e superficiais da Educação Física. Acreditamos que o debate epistemológico se encontra distante de resoluções mais abrangentes, no entanto, isto não exime os docentes de buscarem constantemente 0 envolvimento com a vanguarda científica, bem como um aprofundamento nos conceitos curriculares. A área precisa cruzar muitas fronteiras, desnaturalizar identidades, romper com discursos dominantes e produzir novos discursos que a direcionem para o caminho da equidade social.

$\mathrm{Na}$ urgência dessas transformações, acreditamos que as identidades solitárias só esvanecerão em conjunturas do Ensino Superior que facilitem a comunicação docente com seus pares e com a comunidade acadêmica, proporcionando instrumentos de ensino e pesquisa que possibilitem o enfrentamento dos desafios contemporâneos em tempos neoliberais. Por fim, ressaltamos a urgência de cambiarmos as identidades solitárias por identidades solidárias. Trata-se de uma ação articulada a um projeto mais amplo e importante, qual seja, reforçar o Ensino Superior como esfera democrática e polo de transformação social.

\section{REFERÊNCIAS}

BRACHT, Valter. Identidade e crise da Educação Física: um enfoque epistemológico. In: BRACHT, Valter; CRISÓRIO, Ricardo (Org.). A Educação Física no Brasil e na Argentina: identidade, desafios e perspectivas. Campinas: Autores Associados, 2003. p. 13-29.

BRASIL. Lei no 9.394, de 20 de dezembro de 1996. Estabelece as diretrizes e bases da educação nacional. Disponível em: <http://www.planalto.gov.br/ccivil_03/leis/L9394.htm>. Acesso em: 25 abr. 2016.

BURKE, Peter. Hibridismo cultural. São Leopoldo: Unisinos, 2006.

CASTELLANI FILHO, Lino. Educação física no Brasil: a história que não se conta. Campinas: Papirus, 1988.

ESCOSTEGUY, A. C. Estudos Culturais: uma introdução. In: SILVA, T. T. (Org.). 0 que é, afinal, estudos culturais? Belo Horizonte: Autêntica, 2006. p. 133-167.

GENTILI, Pablo. Pedagogia da exclusão. Petrópolis: Vozes, 2011.

GIROUX, Henry. Atos impuros: a prática política dos Estudos Culturais. Porto Alegre: Artmed, 2003. 
GIROUX, Henry. Ensino superior, para quê? Educar, Curitiba, n. 37, p. 25-38, maio/ago. 2010.

HALL, Stuart. A identidade cultural na pós-modernidade. Rio de Janeiro: DP\&A, 2001.

HALL, Stuart. Quem precisa de identidade? In: SILVA, Tomaz Tadeu. Identidade e diferença: a perspectiva dos Estudos Culturais. Petrópolis: Vozes, 2008. p. 103-133.

JOHNSON, Richard. O que é afinal estudos culturais? In: SILVA, T. T. O que é afinal estudos culturais? Belo Horizonte: Autêntica, 2006. p. 07-132.

MCLAREN, Peter; GIROUX, Henry. Escrevendo das margens: geografias de identidade, pedagogia e poder. In: MCLAREN, Peter. Multiculturalismo revolucionário: pedagogia do dissenso para novo milênio. Porto Alegre: Artmed, 2000. p. 25-50.

MEIHY, João Carlos Sebe Bon. Manual de história oral. São Paulo: Loyola, 1996.

MEIHY, João Carlos Sebe Bon; HOLANDA, Fabíola. História oral: como fazer, como pensar. 2. ed. São Paulo: Contexto, 2010.

NEIRA, Marcos Garcia. Desvelando Frankensteins: interpretações dos currículos de licenciatura em Educação Física. Revista Brasileira de Docência, Ensino e Pesquisa em Educação

Física, Cristalina, v. 1, n. 1, p. 118-140, ago. 2009.

NEIRA, Marcos Garcia; NUNES, Mário Luiz Ferrari. Pedagogia da cultura corporal: crítica e alternativas. São Paulo: Phorte, 2006.

NEIRA, Marcos Garcia; NUNES, Mário Luiz Ferrari. Educação física, currículo e cultura. São Paulo: Phorte, 2009.

NUNES, Mário Luiz Ferrari. Frankensteins, monstros e o Ben 10: fragmentos da formação inicial em Educação Física. Tese (Doutorado em Educação) - Faculdade de Educação, Universidade de São Paulo, São Paulo, 2011.

SILVA, Tomaz Tadeu. A produção social da identidade e da diferença. In: SILVA, Tomaz Tadeu da (Org.). Identidade e diferença: a perspectiva dos Estudos Culturais. Petrópolis: Vozes, 2008. p. 73-102.

SILVA, Tomaz Tadeu. Documentos de identidade: uma introdução às teorias do currículo. Belo Horizonte: Autêntica, 2007.

VIEIRA, Rubens Antonio Gurgel. Identidades docentes no ensino superior de Educação Física: um recorte da cidade de Sorocaba. Dissertação (Mestrado) - Faculdade de Educação, Universidade de São Paulo, São Paulo, 2013.

WOODWARD, Kathryn. Identidade e diferença: uma introdução teórica e conceitual. In: SILVA, T. T. Identidade e diferença: a perspectiva dos estudos culturais. Petrópolis: Vozes, 2008. p. 7-72. 